\title{
Serum uric acid and renal function in patients with type 1 diabetes: a nationwide study in Brazil
}

\author{
Marcela Haas Pizarro ${ }^{1 *}$, Deborah Conte Santos ${ }^{1}$, Bianca Senger Vasconcelos Barros ${ }^{1}$, \\ Laura Gomes Nunes de Melo² and Marilia Brito Gomes ${ }^{1}$
}

\begin{abstract}
Background: Diabetes nephropathy is a microvascular complication associated with high morbidity and mortality in patients with type 1 diabetes, and its pathogenesis is not fully understood. Our aim was to evaluate the association between levels of serum uric acid and renal function assessed by glomerular filtration rate (GFR) and albuminuria in patients with type 1 diabetes.
\end{abstract}

Methods: This is a multicenter, cross-sectional, observational study with 1686 patients, conducted between August 2011 and August 2014 in 14 public clinics from ten Brazilian cities. Renal function was estimated by CKD-EPI (adults) and by Schwartz (adolescents).

Results: We analyzed 1686 patients, aged $30.1 \pm 12.0$, with $15.4 \pm 9.3$ years of duration of diabetes; $55.8 \%$ were female and $54.0 \%$ were Caucasians. Serum uric acid was related to renal function, with a mean of $4.8 \pm 1.4$ (in the normal renal function group) vs $5.2 \pm 2.0$ (GFR $\geq 60 \mathrm{ml} / \mathrm{min}$ and albuminuria) vs $6.5 \pm 2.6 \mathrm{mg} / \mathrm{dl}$ (GFR $<60 \mathrm{ml} / \mathrm{min}$ ). $\mathrm{ln}$ the pooled group, multivariate analysis showed an inverse correlation between serum uric acid and GFR ( $r=-0.316$, $\mathrm{p}<0.001$ ) with a decrease of $4.11 \mathrm{ml} / \mathrm{min}$ in the GFR for every increase of $1 \mathrm{mg} / \mathrm{dl}$ in serum uric acid. Considering only patients with normal renal function $(n=1170)$, a decrease of $2.04 \mathrm{ml} / \mathrm{min}$ in the GFR for every increase of $1 \mathrm{mg} / \mathrm{dl}$ in Serum uric acid was noted using multivariate analysis.

Conclusions: Patients with higher levels of serum uric acid have worse renal function, independently of $\mathrm{HbA} 1 \mathrm{c}$ or duration of diabetes, which persisted even in patients with normal renal function. Further prospective studies are necessary to establish if patients with higher serum uric acid may have an elevated risk for developing chronic kidney disease.

Keywords: Type 1 diabetes, Serum uric acid, Glomerular filtration rate, Chronic renal disease, Albuminuria

\section{Background}

Type 1 diabetes (T1D) is a chronic autoimmune disease which incidence is increasing worldwide [1]. Diabetesrelated chronic complications resulting in elevated morbidity and mortality is still a concern in these patients

\footnotetext{
*Correspondence: marcelahpizarro@gmail.com

${ }^{1}$ Department of Internal Medicine, Diabetes Unit, State University of Rio de Janeiro (UERJ), Rio de Janeiro, Rio de Janeiro, Brazil

Full list of author information is available at the end of the article Brazilian Type 1 Diabetes Study Group (BrazDiab1SG). Membership of the Brazilian Type 1 Diabetes Study Group is provided in the Acknowledgments section
}

[2]. Even though diabetic nephropathy (DN) is one of the most prevalent of such complications, its pathogenesis is not fully understood. Diabetes is responsible for $30-50 \%$ of all chronic kidney disease (CKD) [2] and is the main cause of renal failure requiring renal replacement therapy worldwide. This leads to a significant burden to public health [3]. Additionally, in T1D, the presence or severity of end-stage kidney disease was the main determinant of excess mortality, mainly from cardiovascular disease, independently of the use of statins or inhibitors of the renin-angiotensin system [4]. 
The physiopathology of chronic microvascular complications of T1D is complex, involving the interaction between genetic susceptibility, metabolic, and environmental factors. Many risk factors have already been associated with the development and progression of diabetic nephropathy, such as elevated HbA1c, duration of diabetes, presence of concomitant microvascular complications (especially retinopathy [5]) and elevated albumin excretion rate [6]. However, despite the increase in the use of renoprotective treatment and a more aggressive treatment of hypertension and diabetes, the risk of end-stage renal disease did not change over the years in a population of Caucasians patients with T1D that attended the Joslin Clinic [7].

Recent studies reveal that high serum uric acid (SUA) could also be a risk factor for DN $[8,9]$. Studies disagree on whether uric acid has oxidant or antioxidant properties. In vitro studies show that uric acid may have antioxidant properties. SUA works as a scavenger of free radicals, reacting with a series of oxidants, especially peroxynitrite [10]. Other studies, both in vitro and in vivo, suggest that high levels of SUA may promote endothelial dysfunction [11], hypertension, and metabolic syndrome by inducing oxidative stress [10]. In fact, there is evidence that the use of drugs that lower serum uric acid can revert these conditions $[12,13]$.

Due to mechanisms not yet fully understood, patients with T1D usually have lower levels of SUA compared with healthy individuals or patients with T2D [14, 15]. One possible cause is glycosuria, leading to uricosuria mediated by activation of glucose transporter 9 (GLUT 9) isoform 2 on the apical membrane of the proximal tubule [14]. However, high-normal levels of SUA in patients with T1D have been recently associated to higher prevalence of DN $[8,9]$. Studies found an $80 \%$ elevation in the risk of developing albuminuria per $1 \mathrm{mg} /$ $\mathrm{dl}$ increase in SUA concentration, even in high-normal ranges of SUA [16]. Higher levels of SUA were also associated with a reduced glomerular filtration rate (GFR) estimated by serum Cystatin C [17]. Another study showed that the use of allopurinol was associated with a reduction of SUA, systolic and diastolic blood pressure, and urinary albumin excretion rate in patients with T2D [18], supporting the association between elevated SUA and DN. Studies with the use of allopurinol are still being conducted in patients with T1D [19]. Since SUA is a potentially modifiable risk factor for $\mathrm{DN}$, a complication associated with high morbimortality, further investigation is needed.

The goal of this study is to examine the association between levels of SUA and the presence of CKD, determined by the GFR and albuminuria, in patients with T1D in a multicenter, cross-sectional, observational study.

\section{Methods}

This is a multicenter, cross-sectional, observational study performed by the Brazilian type 1 Diabetes Study Group (BrazDiab1SG) with 1760 patients with T1D, from 14 public clinics of the secondary and tertiary care levels located in ten cities among all geographical areas of Brazil. Data were collected between August 2011 and August 2014. The methods have been described previously [20].

Briefly, all patients received health care from the National Brazilian Health Care System. Each clinic provided data from at least 50 patients with T1D that attended the center. An endocrinologist followed all patients in secondary or tertiary centers. Inclusion criteria were: patients with 13 years of age or older, medical follow-up for at least 6 months at the respective center, patients with at least 5 years of diagnosis of T1D, and diagnosis of T1D by a physician. T1D was diagnosed based on the presence of classic clinical presentation at the moment of the diagnosis, such as polyuria, weight loss, polydipsia, and the need for continuous insulin use since the moment of the diagnosis. Exclusion criteria were: pregnancy or lactation at the moment of inclusion, history of renal transplant, and acute infection or ketoacidosis in the 3 months before the recruitment.

Patients between 13 and 19 years of age were classified as adolescents, and patients older than 19 years were considered adults, based on the American Diabetes Association (ADA) criteria [21].

The study was approved by the ethics committee of Pedro Ernesto University Hospital (State University of Rio de Janeiro) and by the local ethics committee of each center. All participants or their parents signed the informed consent form.

Patients with disease duration greater than or equal to 5 years were submitted to a screening of chronic complications related to T1D, such as screening for microvascular disease (retinopathy, nephropathy, and peripheral neuropathy).

The following variables were obtained using a questionnaire during a clinical visit: gender, current age (years), race, age at diagnosis of T1D, duration of diabetes (years), smoking status, consumption of alcohol, daily dose of insulin, use of other medications, and associated diseases.

The following clinical variables were evaluated: weight $(\mathrm{kg})$, height $(\mathrm{m})$, body mass index [BMI $\left.\left(\mathrm{kg} / \mathrm{m}^{2}\right)\right]$, systemic blood pressure, heart frequency, and abdominal circumference.

Fasting plasma glucose, levels of HbA1c, creatinine, urea, triglycerides, total cholesterol, high-density lipoprotein (HDL) cholesterol, low-density lipoprotein (LDL) cholesterol levels measured during the last clinical visit were obtained from the patient's medical record. The levels of $\mathrm{HbA} 1 \mathrm{c}$ and SUA were measured in a single center. 
HbA1c was measured using high-performance liquid chromatography (HPLC, Bio-Rad Laboratories, Hercules, California, USA). Fasting plasmatic glucose, HDL cholesterol, total cholesterol, triglycerides, and SUA were measured using enzymatic techniques. SUA was measured using an uricase-based commercial kit (BioSystem) with results expressed in milligrams per deciliter (mg/ $\mathrm{dl}$ ) and normal range between $3.5-7.2 \mathrm{mg} / \mathrm{dl}$ in men and $2.6-6.0 \mathrm{mg} / \mathrm{dl}$ in women. Friedewald's equation was used to calculate LDL cholesterol values [22]. Creatinine was measured using a colorimetric assay kit (Biosystems).

Albuminuria was measured from a morning urine sample. This procedure was repeated twice with a minimal interval of 1 week and maximal of 6 months between each collected sample. The dosage of urinary albumin was evaluated by immunoturbidimetry and the results were expressed as mean $(\mathrm{mg} / \mathrm{dl})$. Albuminuria was defined as albuminuria $\geq 30 \mathrm{mg} / \mathrm{dl}$ [2]. Samples with hematuria or urinary infection were excluded based on a urinalysis performed before the collection of urine for albuminuria. All patients were instructed to avoid physical exercise before the collection of the urine sample.

Renal function was estimated by the CKD-EPI equation [23] in adults and by the Schwartz formula in adolescents [24] and expressed as glomerular filtration rate (GFR) in milliliters per minute per $1.73 \mathrm{~m}^{2}(\mathrm{ml} /$ $\mathrm{min}$ ). Patients were divided according to levels of renal function into three groups for comparison purposes. Group 1 included patients with a GFR $\geq 60 \mathrm{ml} / \mathrm{min}$ with absence of albuminuria. Group 2 included patients with a GFR $\geq 60 \mathrm{ml} / \mathrm{min}$ and the presence of albuminuria. Finally, patients in group $3 \mathrm{had}$ a GFR $<60 \mathrm{ml} / \mathrm{min}$ with or without albuminuria.

\section{Statistical analysis}

Continuous variables are presented as the means \pm standard deviations (SD), and medians and interquartile range (IQR) that were also used to perform a boxplot graph. Frequencies and percentages were used to present categorical variables. Differences between categorical variables were assessed using Chi square and differences between independent continuous variables were assessed using Student's t tests or ANOVA with Sidak correction. A Pearson's correlation coefficient was calculated when applicable. A partial correlation was run to determine the relationship between SUA and GFR while controlling for mean albuminuria in the pooled group. All variables included in the multivariate analysis had a significant Pearson coefficient, except for economic status, smoking, and HDL cholesterol (data not shown). We performed a multivariate linear regression using Generalized Linear Models (GLM) to explore the association between SUA and renal function expressed in GFR as the dependent variable. Adjustments were made for potential confounders, such as: HbA1c, BMI, gender, duration of diabetes, ethnicity, years of education, economic status, smoking, systolic and diastolic blood pressure, use of diuretics, statin or inhibitors of the renin-angiotensin system, LDL and HDL cholesterol, and mean albuminuria. The result was not adjusted for age because age is already included in the CKD-EPI equation. The tests were performed initially in all patients (pooled group) and then in a subgroup with normal renal function. All statistical analyses were performed with Statistical Package for Social Sciences (SPSS) 24.0 for Mac. Confidence intervals (95\%) were expressed when indicated. A two-sided $p$ value less than 0.05 was considered significant.

\section{Results}

Participants' demographic and clinical characteristics according to levels of renal function

Among 1760 patients, we excluded 62 patients because data were not available, and twelve because they had a history of renal transplant. The study, therefore, included 1686 (96\%) patients. Clinical characteristics of the patients included in the study are summarized in Table 1. Clinical and demographic data of the studied population stratified into levels of renal function are summarized in Table 2.

The duration of diabetes was longer and the diagnoses of hypertension and dyslipidemia were more prevalent in patients with albuminuria or lower renal function $(\mathrm{p}<0.001)$. The distribution of gender varied according to different levels of renal function, with the percentage of female patients increasing from 53.9 to $69 \%$ when comparing patients with normal renal function and GFR $<60 \mathrm{ml} / \mathrm{min}$, respectively $(\mathrm{p}<0.001)$.

\section{Serum uric acid and renal function in the pooled group}

Higher SUA was observed in patients with GFR $<60 \mathrm{ml} /$ min in comparison to patients in other levels of renal function. A box plot graph (Fig. 1) illustrates the medians of SUA levels in groups, stratified by renal function. Median SUA was $4.8 \pm 1.4 \mathrm{mg} / \mathrm{dl}$ in the group with normal renal function, $5.2 \pm 2.0 \mathrm{mg} / \mathrm{dl}$ in patients with a GFR $\geq 60 \mathrm{ml} / \mathrm{min}$ and micro or macroalbuminuria, and $6.5 \pm 2.6 \mathrm{mg} / \mathrm{dl}$ in patients with GFR $<60 \mathrm{ml} / \mathrm{min}$ $(\mathrm{p}<0.001)$. A negative correlation was observed between the levels of SUA and GFR $(r=-0.316, p<0.001)$. There was a negative partial correlation between SUA and GFR while controlling for mean albuminuria $(-0.302$, $\mathrm{p}<0.001)$.

\section{Multivariate analysis in the pooled group}

A multivariate regression analysis revealed that levels of SUA were negatively correlated with the GFR, even after 
Table 1 Clinical and demographic data of patients in the pooled group

\begin{tabular}{|c|c|}
\hline Variables & All patients \\
\hline N & 1686 \\
\hline Gender, n (\% female) & $942(55.8)$ \\
\hline Age, year & $30.1 \pm 12.0$ \\
\hline Duration of diabetes, year & $15.4 \pm 9.3$ \\
\hline Years of study & $12.2 \pm 3.8$ \\
\hline \multicolumn{2}{|l|}{ Ethnicity, n (\%) } \\
\hline Caucasian & $911(54)$ \\
\hline Non-caucasian & $774(46)$ \\
\hline \multicolumn{2}{|l|}{ Economic status, n (\%) } \\
\hline High & $52(3.1)$ \\
\hline Medium & $764(45.3)$ \\
\hline Low & $815(48.3)$ \\
\hline Very low & $55(3.3)$ \\
\hline \multicolumn{2}{|l|}{ Geographic region, n (\%) } \\
\hline Southeast & $787(46.7)$ \\
\hline South & $223(13.2)$ \\
\hline North/Northeast & $470(27.9)$ \\
\hline Mid-West & $206(12.2)$ \\
\hline \multicolumn{2}{|c|}{ Diabetes management and glycemic control } \\
\hline Insulin dose (units/kg/day) & $0.8 \pm 0.4$ \\
\hline $\operatorname{HbA1c}(\%)$ & $9.0 \pm 2.1$ \\
\hline $\mathrm{HbA1c}(\mathrm{mmol} / \mathrm{mol})$ & $75 \pm 23$ \\
\hline \multicolumn{2}{|l|}{ Cardiovascular risk factors } \\
\hline Cigarette smoking, n (\%) & $89(5.3)$ \\
\hline Hypertension, n (\%) & $294(17.4)$ \\
\hline Dyslipidemia, n (\%) & $359(21.3)$ \\
\hline Systolic blood pressure (mmHg) & $121.6 \pm 16.2$ \\
\hline Diastolic blood pressure $(\mathrm{mmHg})$ & $75.0 \pm 10.4$ \\
\hline Body mass index $\left(\mathrm{kg} / \mathrm{m}^{2}\right)$ & $24.1 \pm 4.1$ \\
\hline Serum uric acid (mg/dl) & $5.1 \pm 1.9$ \\
\hline Mean albuminuria (mg/dl) & $59.3 \pm 309.4$ \\
\hline Waist circumference (cm) & $82.7(11.5)$ \\
\hline
\end{tabular}

$y$ years, data are presented as number (percentage) or mean $\pm S D$

adjustment for the confounding factors $(\mathrm{p}<0.001)$. Every $1 \mathrm{mg} / \mathrm{dl}$ increase in SUA was associated with a decrease of $4.11 \mathrm{ml} / \mathrm{min}$ in the GFR. The final adjusted model using Generalized Linear Models is described in Additional file 1: Table S1.

\section{Serum uric acid in patients with normal renal function}

These 1170 patients had very similar clinical and demographic characteristics when compared to the pooled population. No difference was noted in the HbAlc, with $9.0 \pm 2.1 \%(75 \pm 23 \mathrm{mmol} / \mathrm{mol})$ in the overall studied population and $8.9 \pm 2.0 \%(73.2 \pm 22.2 \mathrm{mmol} / \mathrm{mol})$ in the group with normal renal function. Patients with normal renal function had a lower prevalence of hypertension
(11.1\% vs $17.4 \%)$ and dyslipidemia (17.4\% vs $21.3 \%)$, and a lower SUA $(4.8 \pm 1.4$ vs $5.1 \pm 1.9 \mathrm{mg} / \mathrm{dl})$ when compared to patients in the pooled group. SUA had a negative correlation with the levels of renal function $(r=-0.093$, $p$ : 0.001 ) in these patients with normal renal function.

\section{Multivariate analysis in the group of patients with normal renal function \\ In patients with normal renal function, every $1 \mathrm{mg} /$ $\mathrm{dl}$ increase in SUA was associated with a decrease in $2.04 \mathrm{ml} / \mathrm{min}$ in the GFR. This association persisted even when corrected by the confounding factors. The final adjusted model using Generalized Linear Models is described in Additional file 1: Table S2.}

\section{Discussion}

Our cross-sectional study indicates that patients, from an admixed and multi-ethnic population, with worse renal function have higher levels of SUA, independent of $\mathrm{HbA1c}$, duration of diabetes and other demographic and clinical variables. Patients with normal GFR $(\mathrm{GFR} \geq 60 \mathrm{ml} / \mathrm{min}$ ) and the presence of albuminuria have a higher SUA when compared to those with absence of albuminuria. The partial correlation used to determine the relationship between SUA and GFR while controlling for mean albuminuria showed that albuminuria had very little influence in the relationship between SUA and GFR. This association of SUA and GFR persists even in patients with normal renal function without albuminuria, suggesting that patients with an elevated SUA may have a higher chance of developing CKD.

The causality relationship between SUA and DN is still controversial. Some studies have already confirmed the association between high-normal SUA and the development or progression of DN. A study conducted with adolescents with T1D showed that a higher SUA was correlated with a lower GFR, even when corrected for gender, HbA1c, duration of diabetes, and other confounding factors [25]. This is relevant because adolescents had lower levels of SUA when compared to healthy control subjects [25] and generally don't have other comorbidities such as hypertension or dyslipidemia that are also related to the development of diabetic nephropathy. In our study, the majority of patients were adults. As expected, we found a higher prevalence of comorbidities such as hypertension and dyslipidemia. However, similar results concerning the relationship between SUA and GFR were observed despite correction for these and other confounding factors.

A study conducted with 355 patients with T1D, with 6 years of follow-up, revealed that for each $1 \mathrm{mg} / \mathrm{dl}$ increase in serum uric acid, there was a $40 \%$ increase in the risk of developing early GFR loss. They defined 
Table 2 Characteristics of patients with type 1 diabetes according to groups of renal function

\begin{tabular}{|c|c|c|c|c|}
\hline \multirow[t]{2}{*}{ Variables } & \multicolumn{3}{|l|}{ Groups } & \multirow[t]{3}{*}{$p$ value } \\
\hline & Normal renal function & $\mathrm{GFR} \geq 60 \mathrm{ml} / \mathrm{min}$ and albuminuria & $\mathrm{GFR}<60 \mathrm{ml} / \mathrm{min}$ & \\
\hline$n=1686$ & 1170 & 246 & 270 & \\
\hline Age, (year) & $28.7 \pm 11.7$ & $28.1 \pm 10.0$ & $37.9 \pm 11.7^{*}$ & $p<0.001$ \\
\hline Gender, (\% female) & $631(53.9)$ & $125(50.8)$ & $186(68.8)^{*}$ & $p<0.001$ \\
\hline Duration of diabetes, (year) & $14.1 \pm 9.1$ & $15.2 \pm 7.5$ & $20.8 \pm 9.8^{*}$ & $p<0.001$ \\
\hline Years of study, (year) & $12.3 \pm 3.9$ & $11.9 \pm 3.5$ & $11.8 \pm 3.8$ & $p=0.086$ \\
\hline Insulin dose, (units/kg/day) & $0.86 \pm 0.36$ & $0.94 \pm 0.46^{*}$ & $0.79 \pm 0.36^{*}$ & $p<0.001$ \\
\hline Cigarette smoking, (\%) & $58(5.0)$ & $15(6.1)$ & $16(5.9)$ & $p=0.233$ \\
\hline Hypertension, (\%) & $130(11.1)$ & $45(18.3)^{*}$ & $119(44)^{*}$ & $p<0.001$ \\
\hline Dyslipidemia, (\%) & $203(17.4)$ & $51(20.8)$ & $105(39)^{*}$ & $p<0.001$ \\
\hline Systolic blood pressure (mmhg) & $119.1 \pm 14.1$ & $124.2 \pm 16.1^{*}$ & $129.5 \pm 20.7^{*}$ & $p<0.001$ \\
\hline Diastolic blood pressure (mmhg) & $73.3 \pm 9.4$ & $78.1 \pm 10.6^{*}$ & $79.6 \pm 12.3^{*}$ & $p<0.001$ \\
\hline $\operatorname{BMI}\left(\mathrm{kg} / \mathrm{m}^{2}\right)$ & $24.0 \pm 4.0$ & $24.1 \pm 4.0$ & $24.9 \pm 4.3$ & $p=0.005$ \\
\hline $\mathrm{HbA1c}(\%)$ & $8.9 \pm 2.0$ & $9.9 \pm 2.5^{*}$ & $8.9 \pm 2.0$ & $p<0.001$ \\
\hline $\mathrm{HbA1c}(\mathrm{mmol} / \mathrm{mol})$ & $73.2 \pm 22.2$ & $84.8 \pm 27.2^{*}$ & $73.5 \pm 21.3$ & $p<0.001$ \\
\hline Serum uric acid (mg/dl) & $4.8 \pm 1.4$ & $5.2 \pm 2.0^{*}$ & $6.5 \pm 2.6^{*}$ & $p<0.001$ \\
\hline
\end{tabular}

GFR Glomerular filtration rate ( $\mathrm{ml} / \mathrm{min}), S D$ standard deviation, y years, data are presented as number (percentage), mean $\pm \mathrm{SD}$. ANOVA was used for continuous variables and Chi square test for categorical variables

${ }^{*} \mathrm{p}<0.05$ vs Normal Renal function group

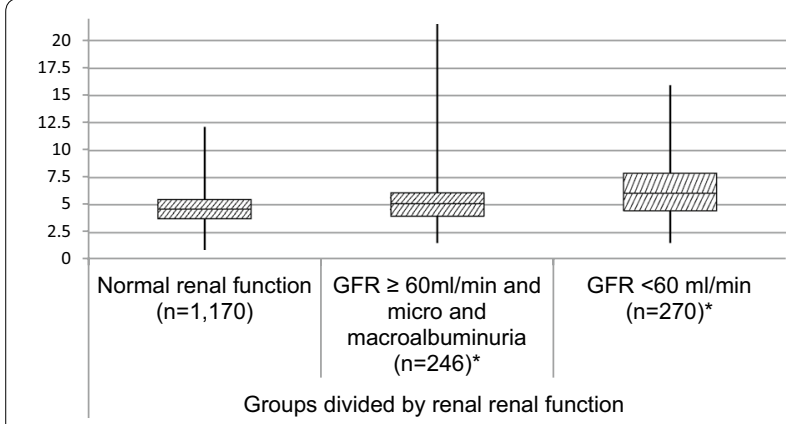

Fig. 1 Boxplot of serum uric acid levels in groups stratified by renal function

progressive renal decline as a loss higher than $3.5 \mathrm{ml} /$ min/year of estimated GFR measured by cystatin. There was a linear increase in this risk of early GFR loss across the normal range of SUA levels [9]. Our study showed similar results, even considering that it is a cross-sectional study. There was a decrease of $4.11 \mathrm{ml} / \mathrm{min}$ with every increase in $1 \mathrm{mg} / \mathrm{dl}$ in SUA, and even patients with normal renal function had a decrease in the GFR with an elevation of SUA. However a recent FINISH cohort study with a follow-up of 3895 patients during 7 years have suggested that serum uric acid was not causally related to diabetic nephropathy but instead, appears to be a downstream marker of kidney damage [26].
Studies show conflicting results as to whether uric acid is a biomarker of renal dysfunction or if it has an etiologic role in the progression of CKD. For instance, patients with CKD that were randomized to receive treatment with allopurinol $100 \mathrm{mg} /$ day had a slower progression of renal disease in comparison with the control group, independently of age, gender, and albuminuria. They also had lower risk of cardiovascular events [27]. Another study showed that hyperuricemic rats had a worse renal function, a higher prevalence of proteinuria, hypertension, and thickening of preglomerular vessels, mediated by the activation of the renin angiotensin system by uric acid. This system could be responsible for an increased glomerular and systemic pressure and also for a direct fibrogenic effect on renal and vascular cells [28]. These effects can be attenuated with the use of their inhibitors [29]. However, in our study, SUA was correlated with a worse GFR, despite the use of inhibitors of the renin angiotensin system, suggesting that other mechanisms could be involved in the renal dysfunction associated with a high SUA. Another possible mechanism could be an impaired nitric oxide production, associated with endothelial dysfunction. Previous data from our group showed similar results, with SUA, even in the upper limit of normality, functioning as a strong predictor of impaired microvascular endothelial function in patients with T1D [30].

A particular strength of our study is the populationbased ascertainment of diabetes cases in a large sample of Brazilian patients with T1D, from a wide range of ethnic 
groups, from all geographic regions of the country. All participating centers followed a uniform and standardized protocol. Similar to other population-based studies, we used a clinical definition of T1D assigned by healthcare providers that was applicable to all patients.

We found that patients with a normal GFR but with the presence albuminuria had a higher SUA when compared to those with normal renal function. However, the difference between the two groups was modest and should be interpreted with caution.

Our study has some limitations. First, it was a crosssectional study so we cannot establish causality between levels of SUA and CKD. We cannot determine if elevated SUA is only a biomarker of the decline of renal function or is also a risk factor for CKD. SUA is eliminated mainly by the kidneys, so it increases as a result of the decline in the GFR. However, the rise in SUA in CKD is generally mild because of enhanced uric acid enteric excretion and a decrease in its production, by reduced xanthine oxidase activity [31]. In the subgroup of patients with normal renal function, without albuminuria, we still found an independent relationship between higher levels of SUA and GFR. This suggests that the elevation of SUA cannot be entirely attributed to the decrease of uric acid filtration rate that accompanies the worsening of renal function. Second, we only included patients that were followed in secondary and tertiary centers, so patients treated in primary clinics were excluded. This probably had little impact in our study since the majority of patients with T1D are followed in secondary and tertiary centers in Brazil. Third, we used the measurement of albumin concentration from a morning sample of urine instead of measurement in urine collected in $24 \mathrm{~h}$. However, studies show that the urinary albumin concentration in a random spot urine is a reliable predictor of diabetic nephropathy and cardiovascular events [32]. Finally, we evaluated albuminuria with a spot urine sample measuring albumin alone, without simultaneously measuring urine creatinine, consequently elevating the risk of false-negative and false-positive results. We decided to measure only the albumin concentration because it is less expensive considering the large sample group analyzed in this study and because it has already been described as a reliable measure in previous studies [32].

\section{Conclusions}

To our knowledge, this is the first study to establish the association between levels of SUA and renal function in patients with T1D in Brazil. We found an association between a decrease in GFR and higher levels of SUA, even when patients had a normal renal function, independently of other confounding factors such as HbA1c, gender, and duration of diabetes. Further prospective studies are necessary to establish if patients with a higher SUA may have an elevated risk for developing CKD. Ongoing randomized, controlled trials with drugs that lower SUA in T1D will establish the relationship between SUA and renal function.

\section{Additional file}

Additional file 1: Table S1. Adjusted regression model for GFR in the pooled group $(n=1686)$. Table S2. Adjusted regression model for GFR in patients with normal renal function $(n=1170)$.

\section{Authors' contributions}

All authors have made substantial contributions to conception and design, analysis and interpretation of data. MP performed the statistical analyses, interpreted the data and drafted the manuscript. DC, BB, LM, and MG made substantial contributions to the discussion, assisted with the data analysis and revised the manuscript critically before submission. All authors read and approved the final manuscript.

\section{Author details}

${ }^{1}$ Department of Internal Medicine, Diabetes Unit, State University of Rio de Janeiro (UERJ), Rio de Janeiro, Rio de Janeiro, Brazil. ${ }^{2}$ Department of Ophthalmology, State University of Rio de Janeiro (UERJ), Rio de Janeiro, Rio de Janeiro, Brazil.

\section{Acknowledgements}

Marilia Brito Gomes (chair), Carlos Antonio Negrato-Brazilian Type 1 Diabetes Study Group BrazDiab1SG Executive steering committee; Marilia Brito Gomes* (mariliabgomes@gmail.com)_Department of Internal Medicine, Diabetes Unit, State University of Rio de Janeiro, Brazil; Roberta Cobas (robertacobas@ gmail.com), Lucianne Righeti Monteiro Tannus (luciannetannus@ig.com. br)—Department of Internal Medicine, Diabetes Unit, State University of Rio de Janeiro, Brazil; Melanie Rodacki*, M.D. (mrodacki2001@yahoo.com.br), Lenita Zajdenverg, M.D. (lenitazaj@gmail.com), Joana Rodrigues Dantas, M.D. (joanardantasp@ig.com.br)_Federal University Hospital of Rio de Janeiro; Maria Lúcia Cardillo Corrêa-Giannella*, M.D. (malugia@lim25fm.usp.br), Sharon Nina Admoni, M.D. (sharonadmoni@ gmail.com), Daniele Pereira dos Santos, M.D. (dps.daniele@ hotmail.com)—Diabetes Unit, University Hospital of São Paulo, São Paulo; Carlos Antonio Negrato*, M.D. (carlosnegrato@uol.com.br), Maria de Fatima Guedes, M.D. (tatiguedeses@hotmail.com)_Bauru's Diabetics Association, Bauru, São Paulo; Sergio Atala Dib*, M.D. (sergio.dib@unifesp. br), Celso Ferreira de Camargo Sallum Filho, M.D. (celsosallum@superig.com. br)—Diabetes Unit, Federal University of São Paulo State, São Paulo; Elisabeth João Pavin*, M.D. (ejpavin@fcm.unicamp.br), Caroline Takano, M.D. (caroline. takano@gmail.com)—Diabetes Unit, University of Campinas, São Paulo; Rosângela Roginski Rea*, M.D. (rosangelarea@uol.com.br), Nicole Balster Romanzini, M.D. (nikbr@hotmail.com)—Clinical Hospital of the Federal University of Paraná; Mirela Azevedo*, M.D. (mirelajobimazevedo@gmail.com), Luis Henrique Canani, M.D. (luishenriquecanani@gmail.com)—Clinical Hospital of Porto Alegre, Rio Grande do Sul; Hermelinda Cordeiro Pedrosa*, M.D. (pedrosa. hc@globo.com), Monica Tolentino (monicatolentino@uol.com.br), Cejana Hamu Aguiar, M.D.--Regional Hospital of Taguatinga, Brasília; Reine Marie Chaves Fonseca*, M.D. (reinemar@terra.com.br), Ludmila Chaves Fonseca M.D., Raffaele Kasprowicz, M.D. (raffaellebarros@hotmail.com)—Diabetes and Endocrinology Center of Bahia; Adriana Costa e Forti*, M.D. (adrianaforti@uol. com.br), Angela Delmira Nunes Mendes, M.D. (angeladelmira@terra.com.br)Diabetes and Hypertension Center of Ceará; Renan Montenegro Junior*, M. D. (renanjr@ufc.br), Virgínia Oliveira Fernandes, M.D. (virginiafernande@hotmail. com)_Federal University of Ceará; João Soares Felício*, M. D. (felicio.bel@terra. com.br), Flavia Marques Santos, M.D. (drafms@bol.com.br)_Federal University Hospital of Pará.

Principal investigators are indicated by an asterisk.

\section{Competing interests}

The authors declare that they have no competing interests. 


\section{Availability of data and materials}

The datasets used and/or analysed during the current study are available from the corresponding author on reasonable request.

\section{Consent for publication}

Not applicable.

\section{Ethics approval and consent to participate}

The study was approved by the ethics committee of Pedro Ernesto University Hospital (State University of Rio de Janeiro) and by the local ethics committee of each center. All participants or their parents signed the informed consent form.

\section{Funding}

This work was supported by grants from Conselho Nacional de Desenvolvimento Científico e Tecnológico do Brasil and Fundação do Amparo à Pesquisa do Estado do Rio de Janeiro.

\section{Publisher's Note}

Springer Nature remains neutral with regard to jurisdictional claims in published maps and institutional affiliations.

Received: 17 January 2018 Accepted: 13 March 2018

Published online: 20 March 2018

\section{References}

1. Atlas IDFD: International Diabetes Federation, Brussels, 2015; 2015.

2. Webster AC, Nagler EV, Morton RL, Masson P. Chronic kidney disease. Lancet. 2017;389(10075):1238-52.

3. McBrien KA, Manns BJ, Chui B, Klarenbach SW, Rabi D, Ravani P, Hemmelgarn B, Wiebe N, Au F, Clement F. Health care costs in people with diabetes and their association with glycemic control and kidney function. Diabetes Care. 2013:36:1172-80.

4. Groop PH, Thomas MC, Moran JL, Wadèn J, Thorn LM, Mäkinen VP, Rosengård-Bärlund M, Saraheimo M, Hietala K, Heikkilä O, et al. The presence and severity of chronic kidney disease predicts all-cause mortality in type 1 diabetes. Diabetes. 2009;58:1651-8.

5. Klein R, Zinman B, Gardiner R, Suissa S, Donnelly SM, Sinaiko AR, Kramer MS, Goodyer P, Moss SE, Strand T, et al. The relationship of diabetic retinopathy to preclinical diabetic glomerulopathy lesions in type 1 diabetic patients: the Renin-Angiotensin System Study. Diabetes. 2005;54:527-33.

6. Radcliffe NJ, Seah JM, Clarke M, Maclsaac RJ, Jerums G, Ekinci El. Clinical predictive factors in diabetic kidney disease progression. J Diabetes Investig. 2017;8(1):6-18.

7. Rosolowsky ET, Skupien J, Smiles AM, Niewczas M, Roshan B, Stanton R, Eckfeldt JH, Warram JH, Krolewski AS. Risk for ESRD in type 1 diabetes remains high despite renoprotection. J Am Soc Nephrol. 2011;22:545-53.

8. Hovind P, Rossing P, Tarnow L, Johnson RJ, Parving HH. Serum uric acid as a predictor for development of diabetic nephropathy in type 1 diabetes: an inception cohort study. Diabetes. 2009;58:1668-71.

9. Ficociello LH, Rosolowsky ET, Niewczas MA, Maselli NJ, Weinberg JM, Aschengrau A, Eckfeldt JH, Stanton RC, Galecki AT, Doria A, et al. Highnormal serum uric acid increases risk of early progressive renal function loss in type 1 diabetes: results of a 6-year follow-up. Diabetes Care. 2010;33:1337-43.

10. Nakagawa T, Kang DH, Feig D, Sanchez-Lozada LG, Srinivas TR, Sautin Y, Ejaz AA, Segal M, Johnson RJ. Unearthing uric acid: an ancient factor with recently found significance in renal and cardiovascular disease. Kidney Int. 2006;69:1722-5.

11. Sautin YY, Johnson RJ. Uric acid: the oxidant-antioxidant paradox. Nucleosides Nucleotides Nucleic Acids. 2008;27:608-19.

12. Sánchez-Lozada LG, Tapia E, Soto V, Avila-Casado C, Franco M, Zhao L, Johnson RJ. Treatment with the xanthine oxidase inhibitor febuxostat lowers uric acid and alleviates systemic and glomerular hypertension in experimental hyperuricaemia. Nephrol Dial Transplant. 2008;23:1179-85.
13. Nakagawa T, Hu H, Zharikov S, Tuttle KR, Short RA, Glushakova O, Ouyang X, Feig DI, Block ER, Herrera-Acosta J, et al. A causal role for uric acid in fructose-induced metabolic syndrome. Am J Physiol Renal Physiol. 2006;290:F625-31.

14. Lytvyn Y, Škrtić M, Yang GK, Yip PM, Perkins BA, Cherney DZ. Glycosuriamediated urinary uric acid excretion in patients with uncomplicated type 1 diabetes mellitus. Am J Physiol Renal Physiol. 2015;308:F77-83.

15. Gołembiewska E, Ciechanowski K, Safranow K, Kedzierska K, KabatKoperska J. Renal handling of uric acid in patients with type 1 diabetes in relation to glycemic control. Arch Med Res. 2005;36:32-5.

16. Bjornstad P, Maahs DM, Rivard CJ, Pyle L, Rewers M, Johnson RJ, SnellBergeon JK. Serum uric acid predicts vascular complications in adults with type 1 diabetes: the coronary artery calcification in type 1 diabetes study. Acta Diabetol. 2014;51:783-91.

17. Rosolowsky ET, Ficociello LH, Maselli NJ, Niewczas MA, Binns AL, Roshan B, Warram JH, Krolewski AS. High-normal serum uric acid is associated with impaired glomerular filtration rate in nonproteinuric patients with type 1 diabetes. Clin J Am Soc Nephrol. 2008;3:706-13.

18. Liu P, Chen Y, Wang B, Zhang F, Wang D, Wang Y. Allopurinol treatment improves renal function in patients with type 2 diabetes and asymptomatic hyperuricemia: 3-year randomized parallel-controlled study. Clin Endocrinol (Oxf). 2015:83:475-82.

19. Maahs DM, Caramori L, Cherney DZ, Galecki AT, Gao C, Jalal D, Perkins BA, Pop-Busui R, Rossing P, Mauer M, et al. Uric acid lowering to prevent kidney function loss in diabetes: the preventing early renal function loss (PERL) allopurinol study. Curr Diab Rep. 2013;13:550-9.

20. Gomes MB, Negrato CA. Adherence to insulin therapeutic regimens in patients with type 1 diabetes. A nationwide survey in Brazil. Diabetes Res Clin Pract. 2016:120:47-55.

21. American Diabetes Association. Standards of medical care 2015. Diabetes Care. 2015;38(Suppl. 1):S41-8

22. Friedewald WTLR, Fredrickson DS. Estimations of serum low density lipoprotein cholesterol in plasma, without use of preparative ultracentrifuge. Clin Chem. 1972;18:499-502.

23. Levey AS, Stevens LA, Schmid CH, Zhang YL, Castro AF, Feldman HI, Kusek JW, Eggers P, Van Lente F, Greene T, et al. A new equation to estimate glomerular filtration rate. Ann Intern Med. 2009;150:604-12.

24. Schwartz GJ, Work DF. Measurement and estimation of GFR in children and adolescents. Clin J Am Soc Nephrol. 2009;4:1832-43.

25. Lytvyn Y, Mahmud FH, Daneman D, Deda L, Dunger DB, Deanfield J, Dalton RN, Elia Y, Har R, Bradley TJ, et al. Association between plasma uric acid levels and cardiorenal function in adolescents with type 1 diabetes. Diabetes Care. 2016;39:611-6.

26. Ahola AJ, Sandholm N, Forsblom C, Harjutsalo V, Dahlström E, Groop $\mathrm{PH}$, FinnDiane Study G. The serum uric acid concentration is not causally linked to diabetic nephropathy in type 1 diabetes. Kidney Int. 2017;91:1178-85.

27. Goicoechea M, de Vinuesa SG, Verdalles U, Ruiz-Caro C, Ampuero J, Rincón A, Arroyo D, Luño J. Effect of allopurinol in chronic kidney disease progression and cardiovascular risk. Clin J Am Soc Nephrol. 2010:5:1388-93.

28. Kang DH, Nakagawa T, Feng L, Watanabe S, Han L, Mazzali M, Truong $L$, Harris $R$, Johnson RJ. A role for uric acid in the progression of renal disease. J Am Soc Nephrol. 2002;13:2888-97.

29. Menè P, Punzo G. Uric acid: bystander or culprit in hypertension and progressive renal disease? J Hypertens. 2008;26:2085-92.

30. Matheus AS, Tibiriçá E, da Silva PB, de Fátima Bevilácqua da Matta M, Gomes MB. uric acid levels are associated with microvascular endothelial dysfunction in patients with Type 1 diabetes. Diabet Med. 2011:28:1188-93.

31. Bjornstad P, Lanaspa MA, Ishimoto T, Kosugi T, Kume S, Jalal D, Maahs DM, Snell-Bergeon JK, Johnson RJ, Nakagawa T. Fructose and uric acid in diabetic nephropathy. Diabetologia. 2015;58:1993-2002.

32. Viana LV, Gross JL, Camargo JL, Zelmanovitz T, da Costa Rocha EP, Azevedo MJ. Prediction of cardiovascular events, diabetic nephropathy, and mortality by albumin concentration in a spot urine sample in patients with type 2 diabetes. J Diabetes Complicat. 2012;26:407-12. 